\title{
1 Long-time course of idiopathic small fiber neuropathy
}

2 Flossdorf P. ${ }^{1}$, Haupt W.F. ${ }^{1}$, Brunn A. ${ }^{2}$, Deckert M. ${ }^{2}$, Fink G.R. ${ }^{1,3}$, Lehmann H.C. ${ }^{1}$, Wunderlich

$3 \mathrm{G}^{1}$

4

$5 \quad{ }^{1}$ Department of Neurology, University Hospital of Cologne, Germany

$6 \quad{ }^{2}$ Department of Neuropathology, University Hospital of Cologne, Germany

$7 \quad{ }^{3}$ Cognitive Neuroscience, Institute of Neuroscience and Medicine (INM-3), Research Center

8 Juelich, Germany

9

Conflicts of Interest Statement:

All authors disclose any sponsorship or funding arrangements relating to their research and all authors disclose any possible conflicts of interest.

19

\section{Correspondence to:}

Dr. Gilbert Wunderlich, Department of Neurology, University Hospital Cologne, Germany, Kerpener Straße 62, D-50937 Köln, phone: 0221-478-84680, fax: 0221-478-87453, email: gilbert.wunderlich@uk-koeln.de 
Keywords:

pain, skin biopsy, intraepidermal nerve fiber density, neurophysiology, polyneuropathy

\section{Abstract}

Background: Small fiber neuropathy (SFN) is a challenging subtype of peripheral neuropathies. Once diagnosis has been established, there is an uncertainty how SFN may progress, whether larger fibers will become involved over time, whether quality of life may be compromised, or whether repeated diagnostic workup in patients with unknown underlying cause may increase the yield of treatable causes of SFN.

Methods: We evaluated 16 patients with documented long-time course of idiopathic SFN.

Results: Clinical and electrophysiological course remained stable in $75 \%$ of the patients, while $25 \%$ SFN-patients developed large fiber neuropathies.

Conclusions: Our data suggest that SFN represents a benign disease course in the majority of patients without severely limiting quality of life.

Introduction

Small fiber neuropathy (SFN) comprises a spectrum of peripheral painful neuropathic conditions characterized by dysfunction of small caliber sensory and/or autonomic nerve fibers $[1,2]$. Mutations of voltage-gated sodium channels in small caliber A-delta- and Cfibers are responsible for generating action potentials in the nociceptive pathway $[3,4]$. This results in a dysbalance of axonal de- and regeneration. As these fibers transmit temperature sensation, contribute to mechanical nociception and regulation of the autonomic nervous system [5], patients with SFN suffer from symptoms such as pain, burning, prickling, temperature disturbance perception, and/or autonomic symptoms. Usually, these symptoms are distributed in a length-dependent pattern while a non-length (patchy) distribution or a pure autonomic neuropathy are rare [6].

Small fibers can be early affected in several pathological circumstances such as metabolic or infectious diseases or genetic disorders [7]. Thus, SFN can also represent an early stage of 
other neuropathies (e.g. diabetic neuropathy) with progression to large fiber neuropathy over time. If an underlying cause cannot be identified, the diagnosis of "idiopathic" SFN can be made. However, at the time point of diagnosis it may be difficult to distinguish "idiopathic" SFN from other neuropathies in which small fibers are also affected, whereas SFN can be excluded, when large fibers are involved as evidenced by pathological nerve conduction studies.

For the diagnosis of SFN, two of the following criteria are required: (a) typical clinical signs of small fiber affection, (b) reduced intraepidermal nerve fiber density or (c) pathological quantitative sensory testing (QST) [8]. However, so far, generally accepted conclusive diagnostic criteria for the identification of affected small fibers have not been agreed on [8,9]. The prevalence of idiopathic SFN without any underlying disease, which in the long run does not convert into a mixed neuropathy is not well known. The few available studies focussing on the time course of idiopathic SFN have described a stable disease for the majority of patients over shorter time periods ranging from two and three years, respectively $[8,12]$. Thus, SFN poses a significant challenge to clinicians and neurophysiologists not only with respect to establishing the diagnosis, but also with regard to monitoring the clinical course. To answer the question how many SFN patients develop other neuropathies or diseases, we followed the long-term clinical course of idiopathic SFN patients.

\section{Patients and Methods}

\section{Patients}

A total of 16 patients diagnosed with SFN at the Department of Neurology and the Department of Neuropathology, University of Cologne, between 2008 and 2014 were recruited retrospectively by reviewing medical records. Diagnostic criteria for SFN were typical clinical symptoms (burning, pain, prickling sensations) and corresponding clinical findings (thermal sensory loss, pinprick sensory loss, hyperalgesia, paresthesia, autonomic symptoms), absence of electrophysiological features of motor and large fiber sensory damage, and skin biopsies confirming reduced density of intraepidermal nerve fibres 
according to the guidelines of the EFNS/PNS $[8,10]$.

All patients received extensive laboratory workup to exclude diabetes mellitus, human deficiency virus (HIV), Sjögren syndrome, systemic lupus erythematodes, rheumatoid arthritis, vasculitis, paraproteinemia, paraneoplastic syndromes, vitamin B12 deficiency, hypothyroidism, renal and hepatic dysfunction, and alcohol abuse. None of the patients had a family history of SFN or neuropathy, and no genetic data were obtained. To determine the patients' quality of life we applied the "Quality of life scale" from the American chronic pain association. This scale ranges from 0-10 (0=non-functioning, 10=normal quality of life) associated with functional ability [11]. Patients were requested to rate their quality of life. As this study was designed as a long-time observation a minimum of a two year-follow-up was required.

\section{Skin biopsy and Neuropathology}

Skin biopsy was performed as a minimum 4x4mm punch-biopsy under lidocaine local anaesthesia. Intraepidermal nerve fiber density (IENFD) was rated and evaluated according to the aged-matched EFNS-guidelines [10].

Skin biopsies of the distal (10 cm proximal to the lateral malleolus) and proximal $(20 \mathrm{~cm}$ distal to the iliac crest) lower extremity - the latter one serving as control were fixed in Zamboni's solution at room temperature for 48 hours and stored in $10 \%$ sucrose solution at $4^{\circ} \mathrm{C}$ for 24 hours. Afterwards, skin specimens were snap-frozen in isopentane (Fluka, Neu-Ulm, Germany), precooled in liquid $\mathrm{N}_{2} .50 \mu \mathrm{m}$ frozen sections were stained with H\&E to ensure the presence of the dermal and epidermal layer. To identify intraepidermal nerve fibers (IENF) immunofluorescence with polyclonal rabbit anti-human PGP 9.5 antibody (DCS, Hamburg, Germany) detected by rabbit biotinylated immunoglobulin coupled with fluorescein isothiocyanate (Sigma, Deisenhofen, Germany) was applied. IENF identified as nerve fibers penetrating the basal membrane from the dermal to the epidermal layer were counted in at least 10 high power fields. The density was calculated at 400x magnification and expressed as number of IENF per section length (IENF/mm) according to the EFNS guidelines [10]. At 
113 least 5 sections per sample were analyzed. Values below the 0.05 quantile values per age

114 span for females and males as published in the EFNS guidelines [10] were considered as pathologically decreased IENFD. Moreover, a normative set for immunofluorescent IENFD was applied [12].

This retrospective study was approved by the institutional ethics board (15-315) and complied with all German federal and state laws.

\section{Results}

All 16 patients (12 females, 4 males, mean age $58 \pm 12$ years) presented with a combination of clinical symptoms. The majority $(n=8)$ initially presented with (thermal-)hypaesthesia, burning sensations $(n=8)$, pain $(n=8)$ or reduced vibration sense $(n=8)$. Three patients reported prickling, one patient additionally complaint of cramps. The observation period ranged from 2.5 to 14 years (mean $5.3 \pm 3.2$ years).

Skin biopsy of all patients revealed a pathological decrease of IENFD in the distal biopsy of the lower extremity as compared to the proximal biopsy (mean 2.0 nerve fibers $/ \mathrm{mm}^{2} \pm 1.1$ range 0.8-5) (Figure 1). Thus, according to the EFNS guidelines, these patients fulfilled the morphological criteria of SFN.

Follow-up examinations including clinical, electrophysiological and therapeutic data were performed in 12 patients (four patients were lost for follow-up). Clinical and electrophysiological studies demonstrated that in $75 \%$ of the patients (9/12), clinical symptoms did not progress and larger caliber sensory or motor neurons remained unaffected. In 3 patients, follow-up examination showed pathological electrophysiological parameters, indicating that initially suspected idiopathic SFN had progressed or converted: one patient developed an idiopathic axonal-demyelinating sensorimotor neuropathy, in two patients tibial evoked potentials revealed pathologically increased latencies.

Six/nine patients with persisting SFN on follow-up examination were taking pain medication on a regular basis, whereas 3 patients did not require pharmacological treatment and had never been on any specific pain medication (table 1). Drugs against neuropathic pain 
141 (gabapentin, pregabalin) were taken by 4 subjects, while 2 patients were on other pain

142 medication (ibuprofen, metamizole).

143 Regarding the subjects' self estimation of their clinical symptoms 4/9 patients with persisting 144 SFN reported worsening over time, while 5 patients estimated symptoms to be unchanged or improved (table 1). Two SFN patients reported improvement of symptoms upon increase of medication (gabapentin 1200 mg/day increased to 1600 mg/day) or spontaneously.

147 Remarkingly, 11/12 patients did not report a limitation in their quality of life (rating 9 or 10),

148 neither at the beginning nor during follow-up. One patient who felt significantly restricted

149 (rating 7) had to attribute this limitation to arthritis. These findings were not gender-specific and independent from the kind of the reported clinical symptoms.

151

152

153

154

155

156

157

158

159

160

161

162

163

164

165

166

167

168
Insert table 1 about here

Insert figure 1 about here

\section{Discussion}

Our study demonstrates that in a long-term course of idiopathic SFN, $75 \%$ of the patients remained stable, while $25 \%$ progressed to a neuropathy that affected also fibers of larger caliber. These findings are in line with results of previous studies concerning the time course of SFN $[8,13]$. Extending the observations of these studies, with a duration of two and 3.25 years, respectively, our considerably longer observation period indicates that SFN can be regarded as stable disease over mean $5.3 \pm 3.2$ years (range $2.5-14$ years).

This finding of a stable disease even over a long time period up to 14 years is reflected by the moderate doses of pain medication, the low impact of SFN on daily life, and the score addressing quality of life. Our SFN patients did not require high doses of medication against neuropathic pain. Rather, the majority of them even did not take any (specific) drugs to alleviate symptoms. Furthermore, they did not feel impaired in daily activities and SFN did not seem to reduce their quality of life.

Although the diagnosis of SFN is frequently made by exclusion, there are various diagnostic 
parameters supporting the diagnosis. Verifying a reduced IENFD via skin biopsy constitutes the "gold standard". Attempts to detect small fiber damage with specific tests as quantitative sensory testing (QST) or quantitative sudomotor axonal reflex (QSART) would be preferable

172 [9], but should not be used as the only diagnostic procedure to establish the diagnosis of SFN [9]. However, if this diagnosis is confirmed by skin biopsy, these tests are not mandatory. Moreover, since these tests are time-consuming they usually are not part of

175 routine diagnostic procedures. We therefore suggest that a combination of the patients'

176 history and complaints should foster electrophysiological studies to exclude large fiber

177 neuropathy and involvement of long fiber tracts. These studies together with a reduced

178 intraepidermal nerve fiber density proven by skin biopsy are sufficient for the diagnosis of

179 SFN.

180 Existing guidelines currently offer no advice how to handle follow-up examinations. Clinical

181 examination and electrophysiological studies seem to be the most suitable method to

182 distinguish between stable idiopathic SFN patients and those who develop other

183 neuropathies. Lauria and coworkers suggested serial skin biopsies and showed that the

184 regrowth rate of intraepidermal nerve fibers can be used as a marker for developing a

185 peripheral neuropathy $[10,14]$. For routine follow-up we consider this too invasive as the

186 development of large fiber neuropathy can be detected applying electrophysiological studies.

\section{Conclusion}

189 The majority of patients with idiopathic SFN remain stable over a long time period in terms of 190 clinical parameters, pain control and daily living. In the future, larger prospective studies are 191 required to detect (genetic) cause of SFN and to monitor its clinical course. Re-evaluation can be restricted to precise clinical and electrophysiological examination.

\section{References}

195 1. Hoitsma, E., et al., Association of small fiber neuropathy with cardiac sympathetic dysfunction in

196 sarcoidosis. Sarcoidosis Vasc Diffuse Lung Dis, 2005. 22(1): p. 43-50.

197 2. Tavee, J. and L. Zhou, Small fiber neuropathy: A burning problem. Cleve Clin J Med, 2009. 76(5): p. 
297-305.

3. Faber, C.G., et al., Gain-of-function Nav1.8 mutations in painful neuropathy. Proc Natl Acad Sci U S A, 2012. 109(47): p. 19444-9.

4. $\quad$ Brouwer, B.A., et al., Painful neuropathies: the emerging role of sodium channelopathies. J Peripher Nerv Syst, 2014. 19(2): p. 53-65.

5. Stewart, J.D., P.A. Low, and R.D. Fealey, Distal small fiber neuropathy: results of tests of sweating and autonomic cardiovascular reflexes. Muscle Nerve, 1992. 15(6): p. 661-5.

6. $\quad$ Freeman, R., Autonomic peripheral neuropathy. Lancet, 2005. 365(9466): p. 1259-70.

7. $\quad$ Lauria, G., Small fibre neuropathies. Curr Opin Neurol, 2005. 18(5): p. 591-7.

8. Devigili, G., et al., The diagnostic criteria for small fibre neuropathy: from symptoms to neuropathology. Brain, 2008. 131(Pt 7): p. 1912-25.

9. Lefaucheur, J.P., et al., Diagnosis of small fiber neuropathy: A comparative study of five neurophysiological tests. Neurophysiol Clin, 2015. 45(6): p. 445-55.

10. Lauria, G., et al., European Federation of Neurological Societies/Peripheral Nerve Society Guideline on the use of skin biopsy in the diagnosis of small fiber neuropathy. Report of a joint task force of the European Federation of Neurological Societies and the Peripheral Nerve Society. Eur J Neurol, 2010. 17(7): p. 903-12, e44-9.

11. Cowan, P.K. American Chronic Pain Association-Quality of life scale. 2003 [20.11.2017]; Available from:

12. Provitera, V., et al. A multi-center, multinational age- and gender-adjusted normative dataset for immunofluorescent intraepidermal nerve fiber density at the distal leg. Eur J Neurol, 2016. 23: p. 333-8.

13. Khoshnoodi, M.A., et al., Longitudinal Assessment of Small Fiber Neuropathy: Evidence of a NonLength-Dependent Distal Axonopathy. JAMA Neurol, 2016. 73(6): p. 684-90.

14. Lauria, G. and G. Devigili, Skin biopsy as a diagnostic tool in peripheral neuropathy. Nat Clin Pract Neurol, 2007. 3(10): p. 546-57. 


\section{Figure Legend}

228 Figure 1: PGP 9.5 immunofluorescence in distal skin biopsy specimen of patient \#17. Only 229 some nerve fibers penetrate the basal membrane from the dermal into the epidermal layer 230 (asterisks), thus, exhibiting a striking loss of IENF. The dotted line marks the basal 231 membrane as border between the dermal and epidermal layer. Immunofluorescence with 232 rabbit anti-human PGP 9.5 fluorescein isothiocyanate; original magnification $x 400$. 


\begin{tabular}{|c|c|c|c|c|c|c|c|c|c|c|c|c|}
\hline \multirow[t]{2}{*}{ \# } & \multirow{2}{*}{$\begin{array}{l}\text { Age } \\
\text { (y) }\end{array}$} & \multirow[t]{2}{*}{ Sex } & \multirow[t]{2}{*}{ Complaints } & \multirow{2}{*}{$\begin{array}{l}\text { Involved } \\
\text { body } \\
\text { parts }\end{array}$} & \multirow[t]{2}{*}{ IENFD/mm² } & \multirow{2}{*}{$\begin{array}{l}\text { Follow-up } \\
\text { period (y) }\end{array}$} & \multirow{2}{*}{$\begin{array}{l}\text { Follow-up } \\
\text { evaluation }\end{array}$} & \multicolumn{2}{|c|}{ Medication } & \multirow{2}{*}{$\begin{array}{l}\text { Self estimation } \\
\text { over time }\end{array}$} & \multicolumn{2}{|c|}{ Quality of life scale } \\
\hline & & & & & & & & Beginning & Follow-up & & beginning & Follow-up \\
\hline 1 & 37 & $f$ & $\begin{array}{l}\text { burning } \\
\text { pain } \\
\text { hypesthesia }\end{array}$ & $\begin{array}{l}\text { feet } \\
\text { hands }\end{array}$ & 2 & 2.5 & SFN & - & & $\leftrightarrow$ & 10 & 10 \\
\hline 2 & 58 & $f$ & $\begin{array}{l}\text { pain } \\
\text { hypesthesia } \\
\text { other (cramps) }\end{array}$ & feet & 3.5 & 5.25 & o.n. & $\begin{array}{l}\text { Pregabalin } \\
150 \mathrm{mg} / \mathrm{d}\end{array}$ & $\begin{array}{l}\text { Prednisolone } \\
\text { (o.n.) }\end{array}$ & $\downarrow$ & 9 & 9 \\
\hline 3 & 53 & $\mathrm{~m}$ & hypesthesia & feet & 3 & 3.75 & SFN & $\begin{array}{l}\text { Ibuprofen } \\
800 \mathrm{mg} / \mathrm{d}\end{array}$ & $\begin{array}{l}\text { Ibuprofen } \\
800 \mathrm{mg} / \mathrm{d}\end{array}$ & $\downarrow$ & 10 & 10 \\
\hline 4 & 45 & $\mathrm{~m}$ & burning & feet & 3 & 4.75 & SFN & $\begin{array}{l}\text { Gabapentin } \\
600 \mathrm{mg} / \mathrm{d}\end{array}$ & $\begin{array}{l}\text { Pregabalin } \\
150 \mathrm{mg} / \mathrm{d}\end{array}$ & $\downarrow$ & 10 & 9 \\
\hline 5 & 67 & $f$ & $\begin{array}{l}\text { burning } \\
\text { pain }\end{array}$ & $\begin{array}{l}\text { feet } \\
\text { lower } \\
\text { limbs }\end{array}$ & 1.5 & lost & lost & & & & & \\
\hline 6 & 67 & $f$ & $\begin{array}{l}\text { burning } \\
\text { pain }\end{array}$ & $\begin{array}{l}\text { feet } \\
\text { lower } \\
\text { limbs } \\
\text { hands }\end{array}$ & 3 & lost & lost & & & & & \\
\hline 7 & 77 & $f$ & $\begin{array}{l}\text { burning } \\
\text { pain }\end{array}$ & $\begin{array}{l}\text { feet } \\
\text { lower } \\
\text { limbs }\end{array}$ & 1.33 & 10 & SFN & - & - & $\downarrow$ & 10 & 9 \\
\hline 8 & 55 & $f$ & pain & feet & 0.8 & 4 & SFN & - & - & $\leftrightarrow$ & 10 & 10 \\
\hline 9 & 61 & $\mathrm{~m}$ & $\begin{array}{l}\text { pain } \\
\text { hypesthesia }\end{array}$ & feet & 1.42 & 5 & o.n. & - & - & $\leftrightarrow$ & 10 & 10 \\
\hline 10 & 73 & $f$ & $\begin{array}{l}\text { burning } \\
\text { pain }\end{array}$ & $\begin{array}{l}\text { feet } \\
\text { hands }\end{array}$ & $<2.7$ & 2.85 & SFN & $\begin{array}{l}\text { Gabapentin } \\
1200 \mathrm{mg} / \mathrm{d}\end{array}$ & $\begin{array}{l}\text { Gabapentin } \\
1800 \mathrm{mg} / \mathrm{d}\end{array}$ & $\uparrow$ & 7 & 9 \\
\hline 11 & 62 & $f$ & $\begin{array}{l}\text { burning } \\
\text { prickling }\end{array}$ & $\begin{array}{l}\text { feet } \\
\text { hands }\end{array}$ & 1.06 & lost & lost & & & & & \\
\hline 12 & 71 & $f$ & hypesthesia & $\begin{array}{l}\text { feet } \\
\text { hands }\end{array}$ & $<1$ & lost & lost & & & & & \\
\hline 13 & 55 & $f$ & $\begin{array}{l}\text { prickling } \\
\text { hypesthesia }\end{array}$ & $\begin{array}{l}\text { feet } \\
\text { lower } \\
\text { limbs }\end{array}$ & $<1$ & 4.5 & SFN & - & $\begin{array}{l}\text { Pregabalin } \\
150 \mathrm{mg} / \mathrm{d}\end{array}$ & $\downarrow$ & 10 & 9 \\
\hline 14 & 69 & $f$ & hypesthesia & $\begin{array}{l}\text { feet } \\
\text { hands }\end{array}$ & 1.25 & 3.25 & o.n. & $\begin{array}{l}\text { Gabapentin } \\
600 \mathrm{mg} / \mathrm{d}\end{array}$ & $\begin{array}{l}\text { Pregabalin } \\
300 \mathrm{mg} / \mathrm{d}\end{array}$ & $\downarrow$ & 9 & 9 \\
\hline 15 & 42 & $f$ & $\begin{array}{l}\text { prickling } \\
\text { hypesthesia }\end{array}$ & $\begin{array}{l}\text { feet } \\
\text { hands }\end{array}$ & 1.5 & 3.5 & SFN & Metamizole a. n. & $\begin{array}{l}\text { Metamizole or } \\
\text { lbuprofen a. } \mathrm{n} \text {. }\end{array}$ & * & 10 & $6-7$ \\
\hline 16 & 34 & $\mathrm{~m}$ & burning & $\begin{array}{l}\text { feet } \\
\text { hands }\end{array}$ & 5 & 14 & SFN & $\begin{array}{l}\text { Pregabalin } \\
150 \mathrm{mg} / \mathrm{d}\end{array}$ & - & $\uparrow$ & 10 & 10 \\
\hline
\end{tabular}

234 Abbreviations: o.n. $=$ other neuropathy, a. n. $=$ as needed, $\uparrow=$ improved, $\downarrow=$ worse, $\leftrightarrow=$ no change, * $=$ change of symptoms 